\title{
Changes in the heparin neutralising activity of platelet poor plasma after immunisation
}

\author{
I. A. BAKER, C. H. L. HOWELLS, AND J. R. O'BRIEN
}

From the Medical Research Council, Epidemiology Unit, Cardiff; the Regional Public Health Laboratory, University of Wales, Cardiff; and the Portsmouth and South East Hampshire District Pathology Service, St Mary's General Hospital, Portsmouth, Hants, UK

SUMMARY Acute myocardial disease, which may be associated with abnormal platelet activity, has been reported after routine immunisation. Thirty-two army apprentices undergoing immunisation were studied for changes in the heparin neutralising activity (HNA) of platelet poor plasma. HNA increased after immunisation. This increase in HNA may represent an increase in platelet activation but may also relate to changes in acute phase proteins. These changes were not observed in elderly subjects undergoing immunisation with influenza vaccine.

A report of sudden deaths in Finnish conscripts (Koskenvuo, 1976) indicated that a few cases resulted from acute myocardial disease and coronary occlusion after immunisation with typhoid, smallpox, and diphtheria vaccines. Sudden cardiac deaths also occurred soon after swine influenza vaccination in elderly people in the United States (Morbidity and Mortality Weekly Reports (USA), 1976). Experimental evidence exists to suggest that viruses, bacteria, and antigen-antibody complexes can cause aggregation of platelets (Lu, 1958; Packham et al, 1968; Mustard et al., 1969; Pfueller and Lüscher, 1972). Further evidence in animals indicates that platelet aggregates may cause myocardial damage (Mustard, 1972). An investigation was undertaken therefore to discover whether the administration of standard vaccines to young British army apprentices and influenza vaccine to a group of elderly persons resulted in any change in heparin neutralising activity as reflected by change in the heparin thrombin clotting time of platelet poor plasma. This test has frequently been reported to be abnormal in situations where there is presumed platelet activation (Cella and Russo, 1977; O'Brien et al., 1975b). Platelet factor 4 is released from platelets activated at least in vitro, and it then neutralises heparin, but this clinical test does not vary in parallel with assays of PF4 as detected by radioimmunoassay.

Received for publication 30 April 1979

\section{Subjects and methods}

Thirty-two army apprentices aged 16 and 17 years, undergoing immunisation with polio and smallpox vaccines and combined intradermal typhoid, paratyphoid, and tetanus vaccines, had citrated and clotted blood samples taken before and on the 7th, 14th, and 21st days after immunisation. Similar samples were taken from 10 control subjects. These control subjects could not be selected from the apprentices. They were senior staff members with an average age of 42.5 years. Twenty subjects also gave blood samples 24 hours after immunisation. The heparin thrombin clotting time (HTCT) test (O'Brien et al., 1975a) was used to measure the heparin neutralising activity (HNA) of plasma samples. Antibody responses to typhoid $\mathrm{H}$ and $\mathrm{O}$ antigens were determined by standard methods.

Twenty-one elderly persons who were receiving immunisation with killed influenza viruses gave blood before immunisation and on the first and seventh days after immunisation. Blood was taken at the same time from 10 elderly persons acting as controls. The HTCT times and antibody responses to influenza $\mathrm{HI}$ were determined.

\section{Results}

\section{ARMY APPRENTICES}

The mean values for the heparin thrombin clotting times for the pre-immunisation samples and for the days after immunisation are shown in Table 1. 
Analysis of variance of the heparin thrombin clotting times indicated large 'between-day' variation for subjects compared with controls. The 'residual' or 'unexplained' variations were small in both groups.

Table 1 Mean heparin thrombin clotting times $(s)$ : army apprentices

\begin{tabular}{lll}
\hline $\begin{array}{l}\text { Days after } \\
\text { immunisation }\end{array}$ & $\begin{array}{l}\text { Subjects } \\
(n=32)\end{array}$ & $\begin{array}{l}\text { Controls } \\
(n=10)\end{array}$ \\
\hline 0 & $37 \cdot 9$ & $30 \cdot 5$ \\
7 & $31 \cdot 4$ & $31 \cdot 1$ \\
14 & $35 \cdot 8$ & $31 \cdot 9$ \\
21 & $36 \cdot 5$ & $33 \cdot 5$ \\
\hline
\end{tabular}

In the subjects the mean value for the seventh day was significantly lower than the pre-immunisation value $(\mathrm{P}<0.01)$. By the 14 th and 21 st days the HTCTs were returning towards the pre-immunisation value, and both mean times were significantly increased over that for the seventh day $(P<0.01)$.

The appearance of antibodies to the typhoid $\mathrm{H}$ antigen at differing titres is shown in Table 2. Two subjects had existing antibodies before immunisation. Only one subject showed an antibody response within 24 hours of immunisation. No subjects had antibodies to the typhoid $\mathrm{O}$ antigen before immunisation or within 24 hours of the event. Five out of the 32 subjects showed a response on the seventh day after immunisation.

Table 2 Antibody titres to typhoid ' $H$ ' antigen by subjects $(N)$

\begin{tabular}{lllllll}
\hline $\begin{array}{l}\text { Days after } \\
\text { immunisation }\end{array}$ & \multicolumn{2}{l}{ Titres } & & & $N$ \\
\cline { 2 - 6 } & $1 / 25$ & $1 / 50$ & $1 / 100$ & $1 / 250$ & $1 / 500$ & \\
\hline 0 & - & - & - & 1 & 1 & 32 \\
1 & - & - & 1 & -1 & -1 & 20 \\
7 & 6 & 3 & 4 & 5 & 9 & 32 \\
14 & - & - & 2 & 4 & 25 & 32 \\
21 & - & - & 1 & 7 & 23 & 32 \\
\hline
\end{tabular}

All 20 subjects seen on the day after immunisation had a localised inflammatory response around the vaccination site. There was no evidence of any continuing inflammation when all 32 subjects were seen on the seventh day after immunisation, nor any reported generalised reactions. The mean HTCT for the 20 subjects seen on the day after immunisation was 29.9 seconds. This HTCT was 5 seconds shorter than the pre-immunisation value of this subgroup (34.9 seconds) and a statistically significant change $(\mathrm{P}<0.05)$.
ELDERLY SUBJECTS

The mean HTCT values for the elderly subjects and controls are shown in Table 3.

Table 3 Mean heparin thrombin clotting times $(s)$ : elderly subjects

\begin{tabular}{lll}
\hline $\begin{array}{l}\text { Days after } \\
\text { immunisation }\end{array}$ & $\begin{array}{l}\text { Subjects } \\
(n=21)\end{array}$ & $\begin{array}{l}\text { Controls } \\
(n=10)\end{array}$ \\
\hline 0 & $38 \cdot 3$ & $33 \cdot 9$ \\
1 & $38 \cdot 5$ & $34 \cdot 7$ \\
7 & $38 \cdot 3$ & $34 \cdot 4$ \\
\hline
\end{tabular}

No significant change in the HNA of the platelet poor plasma as shown by the HTCT was evident in these subjects. Only one of the 21 subjects showed a rise in antibody titres to $\mathrm{HI}$ antigen by the seventh day. There were no marked local or generalised reactions after immunisation.

\section{Discussion}

The controls showed no change over the study period but had shorter mean clotting times than the apprentices. Age has little or no effect on the clotting time, and the difference in this small group of controls is unexplained.

The increase in the HNA of platelet poor plasma indicated by the decrease of the mean HTCT times occurred in the army subjects within 24 hours of their immunisation, and this activity remained significantly raised for at least seven days. If this increase in HNA reflects platelet factor 4-like activity in response to immunisation, the alteration of activity could relate to the direct action of the live polio virus on platelets or be associated with the local inflammatory response. Inflammation was not apparent clinically on the seventh day after immunisation, but platelets may still have been involved in this process at a subclinical level. The preservative, thiomersal, which was shown by Scott et al. (1978) to aggregate platelets in vitro, was not present in any of the vaccines used. We were able to measure only the antibody response to typhoid immunisation, but this indicated the absence of these antibodies during the increase in levels of HNA.

Andersen and Godal (1977) reported that the acute phase proteins, orosomucoid and $\alpha_{1}$ antitrypsin, present in platelet poor plasma have HNA similar to or greater than that of platelet factor 4 when tested in isolation. Although we were unable to isolate and measure the HNA of these proteins, we were able to estimate their presence by immunoassay in the plasma of the army subjects and controls. Analysis of variance revealed that the "between- 
days' variation of both proteins in the vaccinated subjects was considerably greater than in controls and significantly different from 'residual' values. The mean values for both proteins are shown in Table 4 together with correlation coefficients for the association between HTCT values and each protein on different days. The changes in the two proteins on the seventh and 21st days were in parallel with the changes in HNA and suggest that these changes were part of the systemic response to immunisation and could have contributed to the total HNA.

Table 4 Mean concentrations of orosomucoid and $a_{1}$ antitrypsin $(g / l)$ and correlation coefficients (' $r$ ') with heparin thrombin clotting times: army apprentices

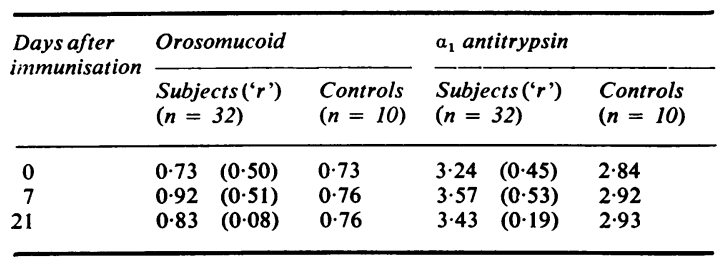

There was no change in the HNA in the plasma of the elderly subjects receiving killed influenza viruses. There were no marked inflammatory reactions. Interestingly, the vaccine contained the preservative, thiomersal. Impaired antibody response in the elderly has been reported previously (Howells et al., 1975).

Immunisation stimulates an acute tissue response and shortening of the heparin thrombin clotting time. A change of platelet activity may occur, and this could be studied by more specific tests of such activity.

We are grateful to the apprentices of the Army Apprentices College, Chepstow and to their medical officer, Dr K. McKelvie; and to the residents of Cartref Homes, Cardiff, for their co-operation in these studies. We are grateful also to Dr J. W. Keyser, M. Etherington, N. Bishop, J. Morgan, and E. Welsby for technical assistance, and to Dr P. Stones, of Glaxo Operation UK Ltd Biologicals, for the donation of the influenza vaccine. $\mathrm{Mr}$ P. Sweetnam gave valuable statistical advice.

\section{References}

Andersen, P., and Godal, H. C. (1977). Heparin tolerance determinating factors evaluated by the heparin thrombin clotting time (Abstract). Thrombosis and Haemostasis, 38, 193.

Cella, G., and Russo, R. (1977). Heparin neutralizing activity (HNA) and antithrombin III in coronary artery disease. Thrombosis and Haemostasis, 38, 696700 .

Howells, C. H. L., Vesselinova-Jenkins, C. K., Evans, A. D., and James, J. (1975). Influenza vaccination and mortality from bronchopneumonia in the elderly. Lancet, 1, 381-383.

Koskenvuo, K. (1976). Sudden deaths amongst Finnish conscripts. British Medical Journal, 2, 1413-1415.

Lu, W. C. (1958). Agglutination of human platelets by influenza (PR8 strain) virus and mumps virus (Abstract). Federation Proceedings, 17, 446.

Morbidity and Mortality Weekly Reports (USA) (1976). 25, 331.

Mustard, J. F. (1972). Platelets and thrombosis in acute myocardial infarction. Hospital Practice, 7, 115-128.

Mustard, J. F., Evans, G., Packham, M. A., and Nishizawa, E. E. (1969). The platelet in intravascular immunological reactions. In Cellular and Humoral Mechanisms in Anaphylaxis and Allergy. Proceedings of the 3rd International Symposium of the Canadian Society for Immunology, Toronto, October, 1968, edited by H. Z. Movat. Karger, Basle, New York.

O'Brien, J. R., Etherington, M. D., Jamieson, S., Lawford, P., Sussex, J., and Lincoln, S. V. (1975a). Heparin neutralising activity test in the diagnosis of acute myocardial infarction. Journal of Clinical Pathology, 28, 975-979.

O'Brien, J. R., Etherington, M. D., Jamieson, S., Lawford, P., Lincoln, S. V., and Alkjaerzig, N. J. (1975b). Blood changes in atherosclerosis and long after myocardial infarction and venous thrombosis. Thrombosis et Diathesis Haemorrhagica, 34, 483-497.

Packham, M. A., Nishizawa, E. E., and Mustard, J. F. (1968). Response of platelets to tissue injury. Biochemical Pharmacology, Supplement, 171-184.

Pfueller, S. L., and Lüscher, E. F. (1972). The effects of immune complexes on blood platelets and their relationship to complement activation. Immunochemistry, 9, 1151-1165.

Scott, S., Mustard, J. F., Chernesky, M., KinloughRathbone, R. L., Greenberg, J. P., and Packham, M. A. (1978). Platelet aggregation induced by swine influenza vaccine (Letter). Lancet, 1, 277-278.

Requests for reprints to: Dr I. A. Baker, MRC Epidemiology Unit (South Wales), 4 Richmond Road, Cardiff CF2 3AS, UK. 